\title{
PREVALENCE OF MOLAR INCISOR HYPOMINERALISATION IN SIX TO EIGHT YEAR-OLDS IN TWO RURAL DIVISIONS IN KENYA
}

\author{
A. M. KEMOLI
}

\begin{abstract}
Objective: To determine the prevalence of molar incisor hypomineralization (MIH) and any associated causes of MIH in children from two rural divisions in Kenya.

Design: Prospective cross-sectional study.

Setting: Seventeen primary schools in Matungulu and Kangundo divisions of Machakos district in Kenya.

Subjects: All six to eight year-olds in the seventeen primary schools.

Results: A total of 3,591 children (55.6\% males and $44.4 \%$ females) were examined for MIH. All the children were from a low socio-economic community with little access to proper medical/dental health care. The prevalence of MIH was $13.73 \%$, with a female to male ratio of 3:1.

Conclusion: The prevalence of MIH of $13.73 \%$ was high in the study population and was probably associated with the poor health conditions that the children went through during the most venerable period of between birth and age three years.
\end{abstract}

\section{INTRODUCTION}

Molar incisor hypomineralisation (MIH), also previously referred to as cheese molar, is a developmental dental condition arising from hypomineralisation of one or all four permanent first molars and sometimes with the involvement of the permanent incisors. This condition is thought to arise from defective enamel formation during the calcification stage (1). The enamel of the affected tooth is less dense, porous and discoloured (white or brown). The affected teeth are often, hypersensitive to temperature changes, brittle, predisposed to dental caries and difficult to anaesthetise. These changes in the teeth can bring about emotional changes in a young patient and lead to difficulties in behaviour management during a dental visit.

It is important to distinguish $\mathrm{MIH}$ from defects like amelogenesis imperfecta which are more generalised. For $\mathrm{MIH}$, one or all the four first permanent molars are affected and sometimes together with one or more permanent incisors. It has to be recognised that the crown calcification of the affected teeth usually takes place in the period from birth to three years. This could explain why the two set of teeth are affected at the same time.
The aetiology of MIH is still unclear, but it has been associated with un-determined environmental and genetic factors that disrupt normal amelogenesis of the affected teeth. Some of the factors associated with this condition have included oxygen deficiency at birth, prenatal and perinatal sickness, high fevers, nephritic diseases, respiratory infections occurring during the period from birth to three years of life. It has also been associated with toxins and antibiotic consumption, malnutrition, intestinal inflammation, diarrhoeas and hypo-parathyroid occurring around the same period (2).

The diagnosis of MIH is clinical. Initially the tooth develops normally but the enamel begins to show areas of weakness and breakage. The affected tooth appears with thinned enamel surface and postoperative demarcated opacities (3). Radiographic evaluation of the affected tooth may show normal morphology of the crown, but reduced enamel opacity that may approach that of the dentine.

$\mathrm{MIH}$ is not comprehensively document in the East African region. However in Europe, it has been shown to have a prevalence rate of $4 \%$ to $25 \%$ (2, 3). From these previous studies, the pattern of its prevalence appears to depend on the age groups, suggesting a phenomenon that may be associated 
with potential environmental-factor(s) $(3,4)$. The objective of the present study was to determine the prevalence and any possible associated causes of $\mathrm{MIH}$ in 6-8 year-old children from two rural Divisions in Machakos District, Kenya.

\section{MATERIALS AND METHODS}

Study design: This was a prospective, cross-section study to determine the prevalence of $\mathrm{MIH}$ in Matungulu and Kangundo Divisions, Machakos District. The study formed part of a general dental examination of children who had been targeted for a clinical study on factors affecting survival rates of proximal ART restorations in primary molars. Ethical approval for the main study had been obtained from the research and ethical committees of Nairobi University and Kenyatta National Hospital, and informed consent for the children's participation obtained from their parents/guardians.

Questionnaire: Seventeen schools with 3,591 children aged six to eight years were randomly selected from a total number of 30 schools that participated in the ART clinical study. Aquestionnaire on demographic information about the child's age, general health, medications and hospitalisation in the first three years of life, oral health habits, feeding habits, parental education, parental profession and the number of siblings in the family was sent to and received from the parent/guardian of all these children, through the school teachers. All the 3,591 questionnaires were answered and returned back.

Clinical examination: Over a period of four weeks in October/November, 2006, three trained final-year dental students paired with three assistants did the dental examination of all the selected children and the documentation of the data obtained. The examiners were first trained on photographs of MIH before being taken through clinical examples. Twenty cases were used by the examiners for pre-test, before allowing them to participate in the study. Doubtful cases were discussed and a consensus reached.

During the examination, each child was made to sit on an ordinary chair in a classroom, facing towards a natural light source. Plaque disclosure was initially done using erythrosine disclosing solution, and scored using Greene and Vermillion technique (5). The diagnosis of MIH was based on visual examination using sterile mouth mirror and dental probe, under natural light, sometimes augmented with aheadlamp/ torch. Using a sterile probe to remove any plaque from the fissures and pits of the first permanent molars and wet and dry sterile cotton gauze to clean and dry the surfaces of these permanent molars and incisors, and with the dental mirror to further illuminate the tooth surfaces, the examiner carefully inspected the coronal part of the first molars and incisors for evidence of enamel hypomineralisation, (Figures 1-3) and documented the results using the criteria in Table 1. The criteria was developed by the author for ease of recording the results by the examiners, as simply present or not present. Only teeth designated with "Arabic numeral one" were considered to have $\mathrm{MIH}$.

Figure 1

Demarcated enamel opacities involving 16

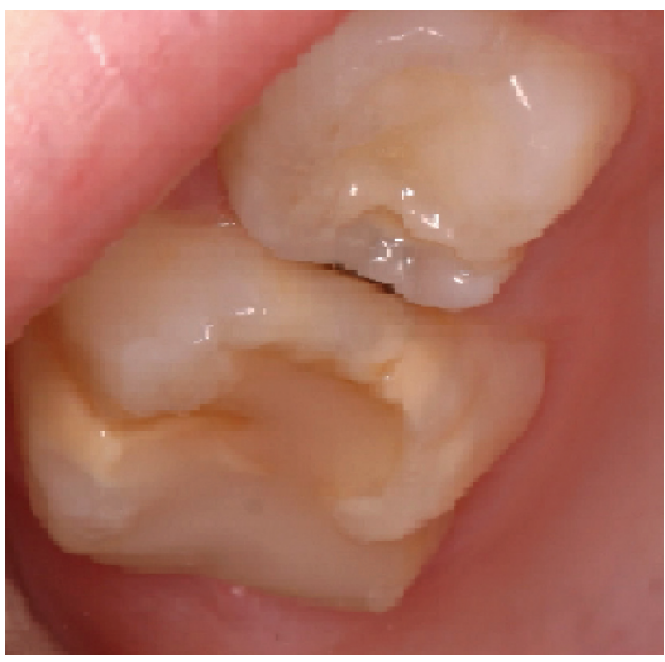

Figure 2

Demarcated enamel opacities of 26, loss of enamel and presence of occlusal caries

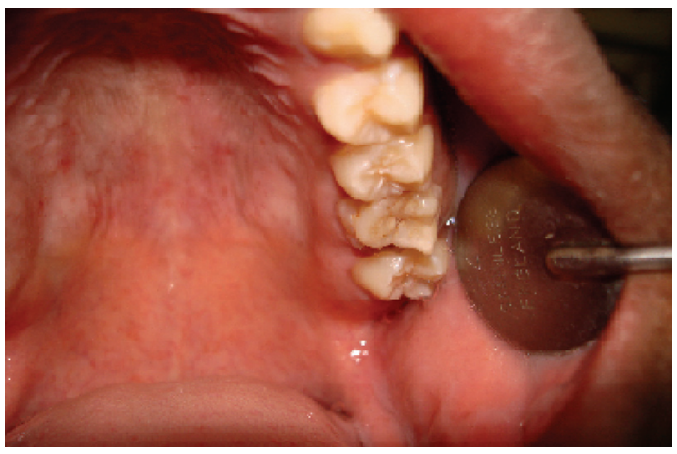

Figure 3

Demarcated enamel opacities involving 11 and 21, and enamel discolouration in some areas

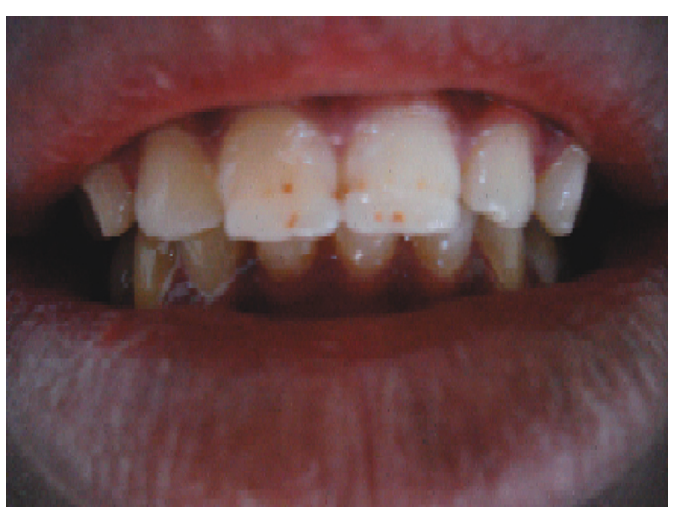


Table 1

The simple diagnostic criteria for MIH as developed by the author

\begin{tabular}{ll}
\hline Code & Criteria \\
\hline 0 & $\begin{array}{l}\text { No opacities, dis-colourations (superficial } \\
\text { or internal), carious lesions other } \\
\text { defects. }\end{array}$ \\
1 & $\begin{array}{l}\text { Demarcated opacities, post-operative } \\
\text { defects of deficiency in the enamel, large } \\
\text { and extensive restorations on any of } \\
\text { these teeth and suspected to be a result } \\
\text { of hypomineralisation. }\end{array}$ \\
\hline
\end{tabular}

Data analysis: The data collected were fed into the computer and analysed using SPSS version 14.0 computer programme. Descriptive data analysis was used to determine the prevalence of MIH in the population, and correlated with the demographic findings made, using Pearson Chi-square test.

\section{RESULTS}

All the 3,591 children $(1,998$ or $55.6 \%$ males and 1,593 or $44.4 \%$ females) from the seventeen primary schools returned the questionnaire and were also examined for MIH. The mean baseline plaque score for the study population was 2.3 (s.d. $=0.45$ ), DMFT was 0.15 (s.d. $=0.52$ ) and the dmft was 3.87 (s.d. $=2.43$ ). The baseline demographic results indicated that most parents of the children $(71.7 \%)$ were either unemployed or peasant farmers (Figure 4), and that most parents $(74.6 \%)$ had no secondary education. Most families (69.1\%) in the study had three or more children and the average number of children per family was four.

Figure 4

Profession of child's parent/guardian

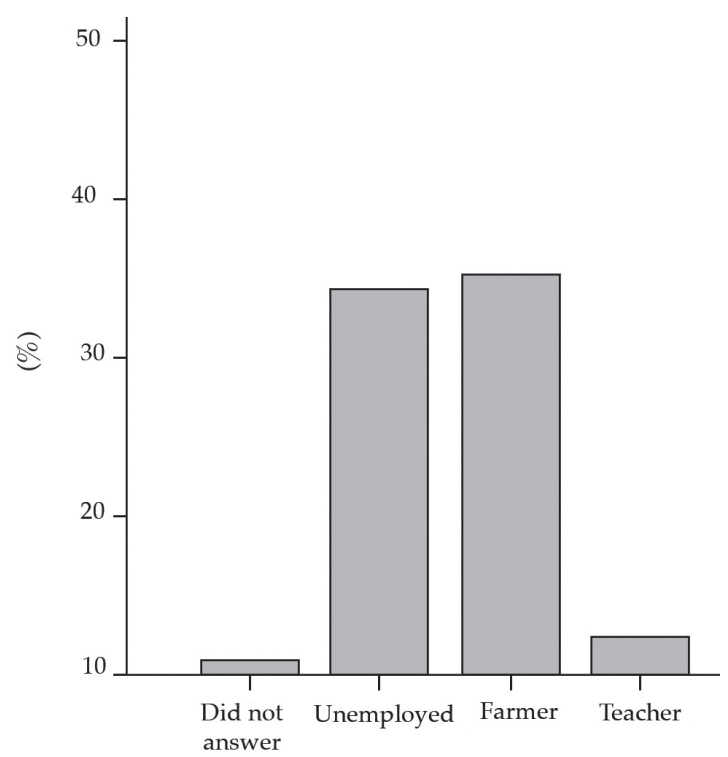

On the health status of the children, 2,011 (56\%) children were reported by their parents to have suffered from some type of illness during the first three years after birth (Table 2), and for the rest of the children, their parents did not respond to the enquiry or could not remember. Amongst the group that were reported to have had some illness, 1,367 $(68 \%)$ children had their parents indicating either not taking the child to any clinic or treating the child with traditional medicines. Financial constraints and long distances to the nearest health centre were the main reasons given for failure to take the children to the clinic. Even for those who took their children to the clinic, none of the parents knew the medicine that was prescribed to the child.

\section{Table2}

The number of children reported to have been sick and the reported sickness

\begin{tabular}{lc}
\hline Type of sickness & No. \\
\hline Fevers & 714 \\
Malaria & 200 \\
Diarrhoea & 311 \\
Measles & 513 \\
Hospitalised & \\
(not stated reasons) & 66 \\
General sickness (not specific) & 207 \\
\hline Total & 2,011 \\
\hline
\end{tabular}

When the schools in the study were categorised (Table 3) into schools that were near to local market centres (within 3 kilometre-radius) and those far from local market centres (more than 3 kilometre-radius), eight schools were placed in the first category and nine in the latter category. Analysis of the location of the school in relationship to the demographic factors showed that 1,540 parents (84\%) of the parents of the children in schools near local market centres tended to be aware of the health needs of their children, taking them to nearby health centres for medical attention and childhood vaccinations. This was not the case with those parents from areas further away (more than three kilometres) from the local market centres. Only a few (483 parents or 27.5\%) of these parents reported doing the same, the rest either used traditional medicines when the child felt un-well, waited for the child to self-heal or did not give any answer to the enquiry.

Responses by the parents on enquiries concerning their knowledge of dental health, $82.3 \%$ of them reported knowing the importance of tooth brushing (Figure 5). However, more than half $(59.3 \%)$ of the same parents also reported that they were unsure whether their children really brushed their teeth regularly. Only $539(15 \%)$ of the parents reported 
regularly helping their children to brush their teeth, the rest had left it to the child irrespective of the age of that child. Of those who assisted their children in brushing their teeth, $243(45 \%)$ reported using a chewing stick, $135(25 \%)$ a commercial toothbrush and the rest $161(30 \%)$ applied both methods. Enquiries on diet and other nutritional requirements for the child gave only a couple of responses that no conclusions could be drawn from.

\section{Figure 5}

Response by parent in regard to the oral hygiene of their children

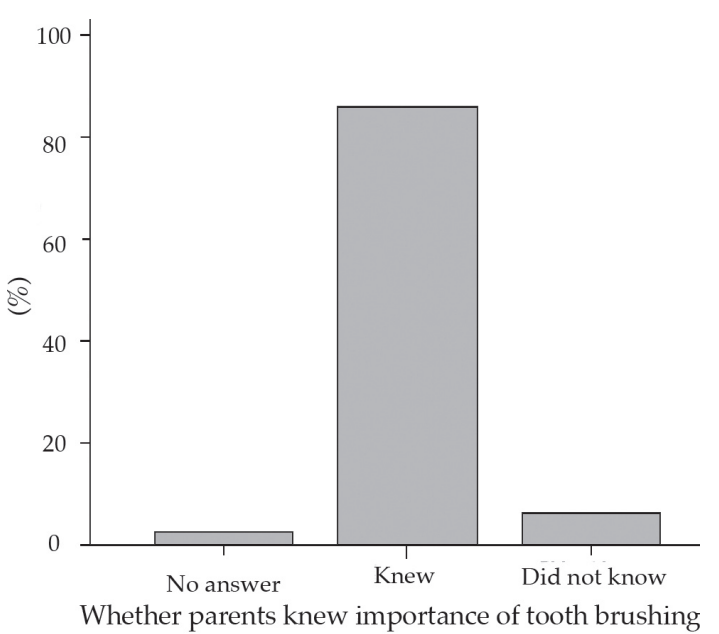

Dental examination results showed most of the children in the study had poor oral hygiene, with plaque index (Greene and Vermillion) of more than two $(66.2 \%)$. Only two $(0.06 \%)$ children had a restoration in one of their teeth that had previously been made, besides the ART restoration that was made during the clinical study. All the other children had no previous restorative work done. A total of 22 $(0.61 \%)$ children examined in the study had their four deciduous canines traditionally removed (traditional canine mutilation), for what the parents termed prevention of childhood infections.

The result of the assessment for the presence of $\mathrm{MIH}$ of the children in the study is given in Table 3. A total of $493(13.73 \%)$ children were found to have $\mathrm{MIH}$ on one or more first permanent molars and incisors. The female subjects had the highest number with $375(76 \%)$ compared to $118(24 \%)$ males who had MIH. Of the children with MIH, 332 (67.3\%) of them had MIH involving either one or more first permanent molars with one or more permanent incisors. The remaining number $161(32.7 \%)$ children had only one or more first permanent molar involved without the involvement of the permanent incisors. None of the teeth with MIH had any restorations.

Table 3

The number of children with MIH and the position of their schools to local market areas

\begin{tabular}{|c|c|c|c|c|}
\hline $\begin{array}{l}\text { School } \\
\text { code }\end{array}$ & $\begin{array}{l}\text { Total number } \\
\text { of children } \\
\text { examined }\end{array}$ & $\begin{array}{l}\text { Total number } \\
\text { of children } \\
\text { with } \mathrm{MIH}\end{array}$ & $(\%)$ & $\begin{array}{l}\text { Position of school from the } \\
\text { local market centre ("Near" was } \\
<3 \mathrm{Km} \text { and "Far" was }>3 \mathrm{Km} \text { ) }\end{array}$ \\
\hline 30 & 116 & 1 & 0.9 & "Near" \\
\hline 31 & 360 & 31 & 8.6 & “Near” \\
\hline 34 & 170 & 14 & 8.2 & "Near" \\
\hline 35 & 188 & 21 & 11.2 & "Near" \\
\hline 39 & 272 & 50 & 18.4 & "Far" \\
\hline 42 & 128 & 30 & 23.4 & "Far" \\
\hline 43 & 238 & 43 & 18.1 & “Far" \\
\hline 44 & 135 & 34 & 25.2 & "Far" \\
\hline 45 & 438 & 45 & 10.3 & “Near” \\
\hline 46 & 240 & 33 & 13.8 & “Near” \\
\hline 47 & 145 & 14 & 9.7 & “Near” \\
\hline 48 & 190 & 19 & 10.0 & “Far" \\
\hline 50 & 239 & 51 & 21.3 & “Far" \\
\hline 52 & 194 & 55 & 9.7 & “Far" \\
\hline 53 & 281 & 29 & 10.3 & "Far" \\
\hline 57 & 177 & 21 & 11.9 & “Near” \\
\hline 58 & 80 & 2 & 2.5 & "Far" \\
\hline Total & 3,591 & 493 (118 & $75 \mathrm{fer}$ & \\
\hline
\end{tabular}


Further analysis of the children with MIH showed that the children from schools that were near to major local markets (within 3 kilometres radius) had slightly lower MIH (235 children or $47.7 \%$ ) than those who camefurther away from these centres (258 children or $52.3 \%)$. The difference was not statistically significant $(\mathrm{p}=0.73)$.

\section{DISCUSSION}

The presentstudy formed part of a clinical examination of six to eight year-old children who were targeted for participation in an ART clinical study. All the children in the study were of low socio-economic background with limited access to any proper dental health care. This may have been one of the reasons that these children had poor oral hygiene and a high dmft of 3.96. (6).

In the present study, most parents reported knowing how to prevent dental diseases, but the poor oral hygiene and high $\mathrm{dmft}$ would suggest that they also seemed not to put the knowledge into practice for the benefit of their children's dental health. The high plaquelevels and $\mathrm{dmft}$ is reminiscent of the poor state of the dental health of these children (6-8 years), and even some of these parents were unsure whether their children brushed their teeth or not, in spite of the parents knowing the importance of regular brushing of the teeth as a dental-disease preventive measure. High poverty levels would also probably contribute to the poor brushing habits as the parents would be unlikely to afford a tooth brush for the children to use (30\% of children used a tooth brush), and even those children who did brush their teeth, $45 \%$ relied on a chewing stick. The high poverty levels could also have contributed to low interest by the parent to provide proper oral health care to their children, plus the potential for insufficient nutritional provision to the children besides the poor management of any existing oral health / general health problems in their children. This would in turn tend to lead to elevated likelihood of the child's susceptibility to childhood diseases and oral health problems. Further more only one poorly equipped public dental clinic was available to this community, but not necessarily accessible by all, and that will tend to complicate the dental health situation for the children.

The prevalence of MIH in this study was comparatively higher than that in the Germany study in 2007, where 1,022 children aged six to twelve years were reported to have had a prevalence rate of $\mathrm{MIH}$ of $5.9 \%$ with one or more first permanent molars with or without the incisor involvement (9). The present Kenyan study had $13.73 \%$ of the children with $\mathrm{MIH}$ that involved one or more first permanent molars with or without incisor involvement. The difference between the two prevalence rates could have been a result of differences in the number of children examined and the age-range disparities between the two studies. In spite of these disparities, in the Germany study, $57.9 \%$ of the children were reported to have MIH involving not only one or more molars but also one or more incisors. In the present study, $67.3 \%$ of the children fell into this category. The present study had more females with MIH than the males. Probably, in the community under study, the female children may have been more predisposed to the causative factors than the male children. The reasons for their increased susceptibility cannot be explained by the present study.

The population in the present study was composed of children from large family units, with poor economic background, low access to general health/oral care and with poor nutritional status. It is probable that the high prevalence of $\mathrm{MIH}$ in the present study population, in general, could be related to the poor conditions in which the children were being raised. The parents who were near to local market centres (within 3 kilometres radius) had easy access to health facilities (private or public) and probably health information than those parents who lived away from these market centres (more than three kilometres radius). MIH was also lower for children in the schools nearer to local market centres than those away from these market centres. But whether this phenomenon was a contributing factor can only be presumed. However, there was a general potential for greater inability for most parents in the study area to adequately provide for the nutritional and health needs of their families given the high poverty levels. In the process, the children would be more likely to be predisposed to malnutrition and poor health that may lead to interference in the proper child development including proper dental development.

Children with MIH tend to require certain urgent dental needs, depending on the severity of the MIH. The needs will depend on the severity of the MIH. The management of MIH can include adequate oral health maintenance, regular fluoride applications, Glass ionomer (GIC) or resin sealing of the affected teeth, restorations for carious teeth with amalgam, GIC, composite, crowns or as a last resort, extraction. Additionally, age, orthodontic situation and radiographic evaluations of the child with $\mathrm{MIH}$ can influence the management regimes of these teeth (10-12). All these needs are obviously unavailable to the community in this study, and given the poor oral health record seen, they will be most vulnerable to dental caries and periodontal disease. The results of the study already suggest that the MIH problem in the child population in the area under study is already a dental health burden. These children are either in need or will soon need dental attention, and yet the parents are unaware and unlikely to meet this burden even when made aware. Given all these problems, these children with MIH and poor oral hygiene, will 
continue to suffer until extraction of the affected teeth can be done, and only when it becomes available to them.

In conclussion, the prevalence of $\mathrm{MIH}$ in the two rural divisions in Machakos, Kenya was $13.73 \%$, and appears to be associated with high poverty levels and poor general health for the children involved, presumably a result of low accessibility to medical health facilities. MIH appears to be a major dental health concern for the child population in this area, with the females appearing to be more susceptible to it than the males.

\section{ACKNOWLEDGEMENTS}

To the three students from ACTA, The Netherlands who examined the children: T.C. Eiloof, S.M.E. Menke and J.T.S. Tjoe A Long; and the three assistants Charity, Martin and Joseph for their data collection and translation of the local language, all the children, parents and teachers of the schools that participated in this study.

\section{REFERENCES}

1. Weerheijm, K.L., Jalevik, B. and Alaluusua, S. Molarincisor hypomineralization. Caries Res. 2001; 35: 390-391.

2. Small, B.W. and Murray, J.J. Enamel opacities: prevalence, classifications and aetiological considerations. J. Dent. 1978; 6: 33-42.
3. Weerheijm, K.L., Groen, H.J., Beentjes, V.E., et al. Prevalence of cheese molars in eleven-year-old Dutch children. ASDC J. Dent. Child. 2001; 68: 259-262.

4. William, V., Masser, L.B. and Burrow, M.F. Molar -incisor hypomineralization: review and recommendations for clinical management. Paediatr. Dent. 2006; 28: 224-232.

5. Greene, J.C. and Vermillion, J.R. The simplified oral hygiene index. J. Am. Dent. Ass. 1964; 68: 7-13.

6. Vargas, C.M., Crall, J.J. and Schneider, D.A. Sociodemographic distribution of paediatric dental caries. NHANES 111 1988- 1994. J. Amer. Dent. Assoc. 1998; 129: 1229-1238.

7. Tinanoff, N. Dental caries risk assessment and prevention. Dent. Clin. North Am. 1995; 39: 709-719.

8. Tinanoff, N. and Douglass, J.Clinical decision-making for caries management in primary teeth. J. Dent. Educ. 2001; 65: 1133-1142.

9. Preusser, S.E., Ferring, V., Wleklinski, C. and Wetzel, W. Prevalence and severity of MIH in a region in Germany- a brief communication. J. Public Health Dent. 2007; 67: 148-150.

10. Fayle, S.A. Molar-incisal hypomineralization restorative management. Eur. J. Paediatric. Dent. 2003; 4: 121-126.

11. Thunold, K. Early loss of the first molars 25 years after. Rep. Congr. Eur. Orthodod. Soc. 1970; 349-365.

12. Jälevik, B. and Klingberg, G. Dental treatment, dental fear and behaviour management problems in children with severe enamel hypomineralization of their permanent first molars. Int. J. Paediatr. Dent. 2002; 12: 24-32. 


\section{GOOD CLINICAL LABORATORY PRACTICE (GCLP) COURSE AT KENYA AIDS VACCINE INITIATIVE}

\section{Description:}

This course is designed to prove comprehensive guidance and practical help for those who are implementing Good Clinical Laboratory Practice in laboratories which undertake the analysis of samples from clinical trials.

The course will address the current regulatory framework for laboratory work in support of clinical trials with reference to the ICH Guideline for Good Clinical Practice, the Clinical EU Trials Directive and related regulations and guidance. The course will also draw on the BARQA guidance document on Good Clinical Laboratory Practice (GCLP).

The course is structured to encourage delegates to:

$\sqrt{ }$ Discuss and develop ideas.

$\sqrt{ }$ Solve specific problems.

$\sqrt{ }$ Examine particular aspects of GCP and GCLP.

\section{Benefits include:}

$\sqrt{ }$ Guidance on the interpretation and application of GCLP within the framework of Good Clinical Practice (GCP).

$\sqrt{ }$ Understand how GCLP fits within a clinical (GCP) programme.

$\sqrt{ }$ Practicalhelp on how to implementGCLP within a clinical research laboratory. $\sqrt{ }$ Anopportunity toupdateyourknowledge of GCLP with the current interpretation of requirements

$\sqrt{ }$ Access to an experienced panel of speakers.

$\sqrt{ }$ An opportunity to improve your understanding of the GCLP requirements as they are applied in different situations.

\section{Who should attend?}

Laboratory managers, analysts, investigators, trial co-ordinators, monitors and auditors working in:

$\sqrt{ }$ Pharmaceutical company laboratories

$\sqrt{ }$ Central laboratories

$\sqrt{ }$ Contract Research Organisations

$\sqrt{ }$ Hospital Laboratories

$\sqrt{ }$ Clinics

$\sqrt{ }$ Investigator sites

\section{Contacts:}

Kenya Aids Vaccine Initiative,

P. O. Box 19676-00202, Nairobi

Tel: $2725405 / 2717694 / 0722207417$

Fax: 2714613

Email: fbashir@kaviuon.org

Website: www.kaviuon.org

Duration of the course: 4 DAYS

Minimum No. of participants: 10 